Bradley, 1960).

That there is no consistent change between drug and control conditions in the distribution of intermediate reaction times seems to indicate that LSD does not change the normal rate of responding. Instead, it affects the overall rate indirectly by producing periods of no responding, which are averaged with periods of responding at the normal rate (Blough, 1963; Migler \& Millenson, 1969). Failure to respond in the presence of a given stimulus, however, can be caused by factors other than the loss of stimulus control (Blough, 1966). Therefore, a discrete trial procedure which allows the animal to make only one of two possible responses to each stimulus may be a more reliable way to assess stimulus control than to measure rate of responding.

\section{REFERENCES}

APPEL, J. B. The effects of "psychotomimetic" drugs on animal behavior. In D. Efron (Ed.), Psychopharmacolog: $A$ review of progress $1957-1967$. Washington, D.C: U.S. Government Printing Office, 1968. Pp. 1211-1222.

BECKER, D. I., APPEL, J. B., \& FREEDHAN, D. X. Some effects of LSD on visual disctimination in pigeons. Psychopharmacologia, 1967, 11, 354-364.

BERRYMAN, R., JARVIK, M. E., \& NEVIN, J. A. Effects of pentobarbital, lysergic acid diethylamide, and chlorpromazine on matching behavjor in the pigeon. Psychopharmacologia, 1962, 3, 60-65.

BLOUGH, D. S. Some effects of drugs on visual discrimination in the pigeon. Annais of the New York Academy of Sciences, 1956, 66, 733-739.

BLOUGH, D. S. Interresponse time as a function of continuous variables: $A$ new method and some data. Journal of the Experimental Analysis of Behavior, 1963, 6, 237-246.

BLOUGH, D. S. Definition and measurement in generalization research. In D. I. Mostofsky (Ed.), Stimulus generalization. Stanford: Stanford University Press, 1965. Pp. 30-37.

BLOUGH, D. S. The study of animal sensory processes by operant methods. In W. K. Honig (Ed.), Operant behavior: Areas of research and application. $\mathrm{Ne}$ W Y r k: Appleton-Century-Crofts, 1966. Pp. 345-379.

BRADLEY, P. B., \& ELKES, J. The effects of some drugs on the electric activity of the brain. Brain, 1957, 80, 77-117.

BRADLEY, P. B., \& KEY, B. J. A comparative study of the effects of drugs on the arousal system of the brain. British Joumal of Pharmacology, 1959, 14, 340-349.

CROSS, D. V., \& LANE, H. L. On the discriminative control of concurrent responses: The relations among response frequency, latency, and topography in auditory generalization. Joumal of the Experimental Analysis of Behavior, 1962, 5, 487-496.

FREEDMAN, D. X., APPEL, J. B., HARTMAN, F. R., \& MOLLIVER, M. E. Tolerance to behavioral effects of LSD-25 in rat. Journal of Pharmacology \& Experimental Therapeutics, $1964,143,309-313$.

GOUREVITCH, G., \& HACK, M. H. Audibility in the rat. Journal of Comparative \& Physiological Psychology, 1966, 62, 289-291.

GUTTMAN, N., \& KALISH, H. I.
Discriminability and stimulus generalization. Joumal of Experimental Psychology, 1956, 51, 79-88.

HANSON, H. M. Effects of discrimination training on stimulus generalization. Joumal of Experimental Psychology, 1959, 58, 321-334.

HOLLISTER, L. E. Human pharmacology of lysergic acid diethylamide. In D. Efron (Ed.), Psychopharmacology: A review of progress 1957.1967. Washington, D.C: U.S. Government Printing Office, 1968. Pp. 1253-1261.

HONIG, W. K., \& DAY, R. W. Discrimination and generalization of a dimension of stimulus difference. Science, 1962, 138, 29.31.

JARRARD, L. E. Effects of d-lysergic acid diethylamide on operant behavior in the rat. Psychopharmacologia, 1963, 5, 39.46.

JARVIK, M. E., \& CHOROVER, S. Impairment by lysergic acid diethylamide of accuracy in performance of a delayed alternation task in monkeys. Psychopharmacologia, 1960,1 , 229-230.

KEY, B. J. The effects of drugs on discrimination and sensory generalization of auditory stimuli in cats. Psychopharmacologia, 1961, 2, 352-363.

KEY, B. J., \& BRADLEY, P. B. The effects of drugs on conditioning and habituation to arousal stimuli in animals.
Psychopharmacologia, 1959-1960. 1, 450-462. MIGLER, B. Etfects of averaging datis during stimulus generalization. Journal of the Experimental Analysis of Behavior. 1964, 7. 303-307.

MIGLER, B., \& MILLENSON, J. R. Analysis of response rates during stimulus generalization. Journal of the Experimental Analysis of Bchavior, 1969, 12, 81-87.

PETERSON. N. J. Some effects of LSD on the control of responding in the cebus monkey by reinforcing and discriminative stimuli. Unpublished MD thesis, Yale Lniversity, 1966.

PIERREL, R. A generalization gradient for auditory intensity in the rat. Journal of the Experimental Analysis of Behavior, 1958, 1. 303-315.

RISLEY, T. Generalization gradients following two-response discrimination training. Joumal of the Experimental Analysis of Behavior, 1964, 1, 199.204.

TERRACE, H. S. Stimulus control. In W. K. Honig (Ed.), Operant beharior: Areas of research and application. New York: Appleton-Century-Crofts, 1966. Pp. 271-344. NOTE

1. Ampules of $0.1 \mathrm{mg} / \mathrm{ml}$ manufactured by Sandoz Pharmaceuticals were obtained from the National Institute of Mental Health, Center for Studies of Narcotics and Drug Abuse.

\title{
Extinction as a function of varied quality and quantity of reward sequence in a straight alley
}

\author{
RAYMOND RUSSIN, WILLIAM N. BOYER, and HENRY A. CROSS \\ Colorado State University, Fort Collins, Colo. 80521
}

Four groups of male albino rats were extinguished in a straight alley after receiving two daily trials on one of the following varied quality and/or quantity of reward sequences: 1 alfalfa pellet followed by 1 sucrose pellet, 1 sucrose pellet followed by 1 alfalfa pellet, a single alfalfa pellet followed by 16 sucrose pellets, and a single sucrose pellet followed by 16 sucrose pellets. The results indicated that a high-quality reward following a low-quality reward produced greater resistance to extinction than when a low-quality reward followed a high-quality reward. The findings were interpreted within Capaldi's sequential theory.

Capaldi (1967) has presented a hypothesis that large rewards following small rewards produce greater resistance to extinction than do large rewards followed by small rewards. According to Capaldi, the first reward provides a trace or "aftereffect," and the second reward conditions this trace in direct proportion with the magnitude of the second reward. Maximum resistance to extinction can therefore be achieved by employing a second reward greater in magnitude than the first reward. Leonard (1969) supported this prediction by showing that smaller rewards on the first trial of a two-trial reward sequence increased resistance to extinction.

Some investigators (e.g., Guttman, 1953; Hutt, 1954) have observed that rats prefer sweeter rewards to less sweet rewards.
Cross, Rankin, \& Wilson (1964) also found that rats receiving a dextrose reward made fewer errors in a multiple-Y maze than did rats receiving an alfalfa-base reward. The Guttman and Hutt studies reported that during extinction more responses were emitted when a preferred quality of reward was used during training.

These studies suggest that quantity and quality have some parallel effects on performance and even on learning measures. If the assumption is made that larger quantities of reward are more preferable than smaller quantities, and if sweeter rewards are more preferable than less sweet rewards, than an extension of Capaldi's sequential hypothesis can be made to include quality of reward. It is conceivable that more preferred rewards, either in terms of quantity or quality, 
following less preferred rewards will produce maximum resistance to extinction.

The present experiment was an attempt to test such an assumption. Four groups of rats were given two trials each day on one of the following conditions: Condition Al-S1 involved a single alfalfa pellet reward on Trial 1 and a single sucrose pellet reward on Trial 2; Condition S1-A1, a single sucrose pellet on Trial 1 and a single alfalfa pellet on Trial 2; Condition A1-S16, a single alfalfa pellet on Trial 1, and 16 sucrose pellets on Trial 2; Condition S1-S16, a single sucrose pellet on Trial 1 and 16 sucrose pellets on Trial 2.

A comparison between Conditions Al-S1 and S1-Al evaluates the hypothesis that the more preferred reward will function similarly to a large quantity of reward. Thus, sucrose following alfalfa, Condition Al-S1, should exhibit greater resistance to extinction than alfalfa following a sucrose reward, Condition S1-A1. In addition, a comparison between the Al-S16 and S1-S16 conditions also determines the effect of quality of reinforcement, since the overall magnitude of the two rewards is the same, differing only in the quality of the first reward. Sequential theory predicts that greatest resistance to extinction should occur in the A1-S16 condition, followed by the S1-S16, A1-S1, and S1-A1 conditions, respectively.

\section{METHOD}

Forty-eight male albino rats, 85 days old, were obtained from Charles River Breeding Laboratories, Wilmington, Mass. The apparatus consisted of a single gray runway, $63 \times 6 \times 12$ in., constructed of $3 / 4$-in. plywood. The start and goal areas were separated from the runway by two hinged doors, which closed microswitches operating a standard electric timer. Noyes 45-mg sucrose and alfalfa pellets were used as rewards. Standard $45-\mathrm{mg}$ Noyes pellets were used during initial goalbox placements.

Upon arrival, the Ss were given food and water on an ad lib basis for 6 days, and then placed on a 23-h food-deprivation schedule for 10 days prior to the start of experimental training. During the adaptation phase, all Ss were individually handled. Three sessions of nonrewarded exploration of the alley were also included during this time. Ss were then assigned randomly to one of the four groups, a given cage housing two animals from the same group. Following exploration, all Ss were given six goal placements, two per day for 3 days. This involved placing $S$ directly into the enclosed goalbox and allowing him to eat the food. During goalbox placements, $S$ s in Groups A1-S1 and S1-Al were given one pellet per
Table 1

Mean Reciprocal Running Speed During Extinction for Four Varied Quality and Quantity of Reward Sequence Groups

\begin{tabular}{lr}
\hline Group & Mean \\
\hline A $1-S 1$ & 9.53 \\
S1 - A 1 & 6.12 \\
A $1-S 16$ & 38.06 \\
S1 - S16 & 27.04 \\
\hline
\end{tabular}

goalbox placement. Ss in the A1-S16 and S1-S16 conditions received four-pellet goalbox placements, duplicating the procedure followed by Leonard (1969). The single-pellet placement for Groups A1-S1 and S1-A1 was used to avoid giving these Ss experience with different quantities of reinforcement.

Following goalbox placements, all Ss were given two acquisition trials per day for 10 days according to their group designation as previously described. Ss were run in squads of four, where each squad contained a single $S$ from each of the four treatment groups. The intertrial interval (ITI) was the time required to run the other three Ss (between 2 and $4 \mathrm{~min}$ ).

On the day following completion of acquisition training, all $S s$ were given nine massed extinction trials, with ITIs between 2 and $4 \mathrm{~min}$. Ss were extinguished using the squad procedure, each $S$ being confined to the nonrewarded goalbox for $30 \mathrm{sec}$.

\section{RESULTS}

Running speeds in the alley were converted to reciprocals and multiplied by 100 for statistical analysis. The running times on the first extinction trial were compared in a single classification analysis of variance to determine if the groups were different at this point. These data yielded a significant difference $(F=3.46, d f=3 / 44$, $\mathrm{p}<.05$ ). A Duncan multiple range test of mean differences indicated a difference between the A1-S16 and S1-S16 groups. No other differences were obtained. The running times for the last eight extinction trials for each of the four treatment groups were combined into four blocks of two trials each. Due to the existing differences at the end of acquisition, an analysis of covariance for a factorial repeated measures design was carried out (Winer, 1962). The results of this analysis indicated a significant effect in extinction due to reward conditions during acquisition $(F=6.24, d f=3 / 39, p<.01)$. The Duncan multiple range test was then used to test adjusted means. All groups were found to be significantly different $(p<.01)$ from each other, with the exception of the A1-S1 and S1-A1 groups.

\section{DISCUSSION}

In general, the results support the extension of sequential theory to include quality of reward. This is clearly demonstrated in the comparison of the A1-S16 and S1-S16 groups, where Ss receiving a single alfalfa pellet followed by 16 sucrose pellets were more resistant to extinction than $\mathrm{Ss}$ who received a single sucrose pellet followed by 16 sucrose pellets. Additional support is found in the order of resistance to extinction for the single-pellet varied-quality reward groups. Resistance to extinction was greater when a sucrose reward followed an alfalfa reward, but the converse was true when the opposite sequence was employed. Table 1 summarizes the running speeds for each of the four groups and the mean values are ordered according to sequential theory's prediction.

The present experiment employed a procedure whereby the single-pellet varied-quality reward groups, A1-S1 and S1-A1, received one pellet during goalbox placements and the varied quality and/or quantity reward groups, A1-S16 and S1-S16, received four pellets prior to acquisition training. Es concerned with manipulating quantity and quality of reward sequences should control for the effects of prior rewards during goal placements. It is conceivable that reward size during goal placements may affect subsequent acquisition and extinction. Although speculative, it seems possible that performance could be influenced when $S$ receives four pellets of reward on six different goal placements and then is confronted with an increase or decrease in reward at the same goalbox. Both the Leonard (1969) study and the present one have not systematically controlled for such preacquisition goalbox placements. Whether or not such an effect exists is a question that needs investigation within sequential theory.

\section{REFERENCES}

CAPALDI, E. J. A sequential hypothesis of instrumental learning. In $K$. W. Spence and J. T. Spence (Eds.), The psychology of learning and motivation: Advances in research and theory. Vol. 1. New York: Academic Press, 1967. Pp. 67-156.

CROSS, H. A., RANKIN, R. J., \& WILSON, J. Influence of amount of reward on maze learning in hooded and albino rats. Psychonomic Science, 1964, 1, 275-276.

GUTTMAN, N. Operant conditioning, extinction, and periodic reinforcement in relation to concentration of sucrose used as reinforcing agent. Journal of Experimental Psychology, 1953, 46, 213-224.

HUTT, P. J. Rate of bar pressing as a function of quality and quantity of food reward. Journal of Comparative \& Physiological Psychology, 1954, 47, 235-239.

LEONARD, D. W. Varied reward sequence and resistance to extinction in the straight alley. Psychonomic Science, 1969, 16, 129-130.

WINER, B. J. Statistical principles in experimental design. New York: McGraw-Hill, 1962. 